\title{
Chronic Type A Aortic Dissection and Giant Aortic Root Aneurysm After Aortic Valve Replacement
}

\author{
Andrés Enríquez Puga, MD', Sara Castaño Rodríguez, MD², Blanca Mateos Pañero, MD², \\ Beatriz Castaño Moreira, $\mathrm{MD}^{3}$, Luis Fernando López Almodóvar, MD ${ }^{4 *}$ \\ ${ }^{1}$ Department of Radiology, Virgen de la Salud Hospital, Toledo, Spain \\ 2 Department of Cardiology, Virgen del Prado Hospital, Talavera de la Reina, Spain \\ ${ }^{3}$ Department of Cardiac Anesthesia, Virgen de la Salud Hospital, Toledo, Spain \\ ${ }^{4}$ Department of Cardiac Surgery, Virgen de la Salud Hospital, Toledo, Spain
}

\begin{abstract}
We describe the case of a 61-year-old male with a giant aortic root aneurysm associated with chronic aortic Type A dissection. The patient had been operated on 16 years before due to aortic annuloectasia with mechanical valve replacement. The patient underwent revision aortic surgery with a Bentall-De Bono operation with Svensson modification, using a \#21 On-X Valsalva mechanical valve conduit. The postoperative course was uneventful.

Copyright $\odot 2016$ Science International Corp.
\end{abstract}

\section{Key Words}

Aortic dissection - Aortic aneurysm • Annuloectasia

\section{Introduction}

Herein we illustrate the surgical management of a giant aortic root aneurysm with aortic dissection in a patient that had been operated on several years before due to aortic annuloectasia with an aortic valve replacement.

\section{Case Presentation}

A 61-year-old male patient had undergone

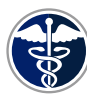

Fax +1 2037853552

E-Mail: aorta@scienceinternational.org

http://aorta.scienceinternational.org

\author{
(C) 2016 AORTA \\ Published by Science International Corp. \\ ISSN 2325-4637 \\ Accessible online at: \\ http://aorta.scienceinternational.org
}

aortic valve replacement due to aortic annuloectasia using a \#23 St. Jude Medical mechanical valve prosthesis. A $4.5-\mathrm{cm}$ aortic root aneurysm was not removed, probably because the aortic valve was trileaflet. By 2007, the aortic root had grown to $7 \mathrm{~cm}$, but surgery was not performed at another institution due to the high risk, so the patient stopped follow-up.

In 2015, the patient was admitted to our hospital with thoracic pain. Computed tomography revealed a $11.3 \times 10.7 \times 10.1-\mathrm{cm}$ aortic root aneurysm with a Stanford Type A dissection (Figures 1 and 2). The patient underwent aortic root surgery (Figure 3 ) with removal of the previous prosthesis and Bentall procedure using a \#21 On-X Valsalva mechanical valve conduit. The distant left main coronary ostium was easily reattached to the ascending conduit via a 10-mm interposition graft (Svensson modification [1]). The right coronary artery button was easily mobilized and conventionally reattached (Figure 4).

Pathology showed a chronic dissection with an intimal tear close to the origin of the left main coronary ostium. Histology showed subendothelial fibrosis with calcified areas due to atherosclerosis.

The postoperative course was uneventful, and the patient was discharged home on postoperative day 8 .

\footnotetext{
* Corresponding Author:

Luis Fernando López Almodóvar, MD

Department of Cardiac Surgery

Virgen de la Salud Hospital

Avda. Barber 30, 45005 Toledo, Spain

Tel.: +34 9252692 00; Fax: +34 9252692 58; E-Mail: lopezalmodovar@yahoo.es
} 


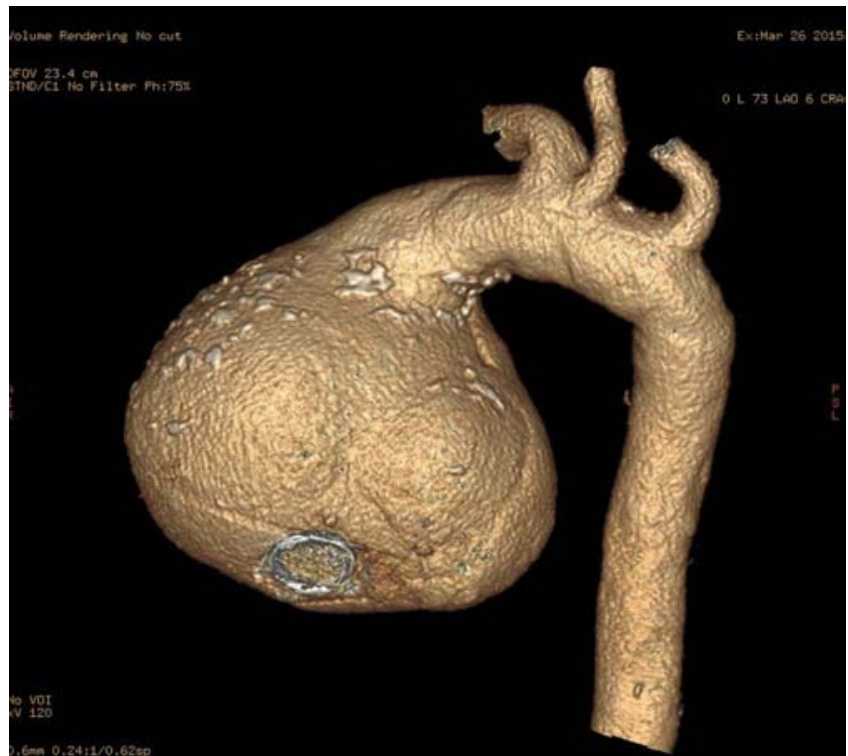

Figure 1. Preoperative $3 D$ computed tomography scan reconstruction of the giant root aneurysm.

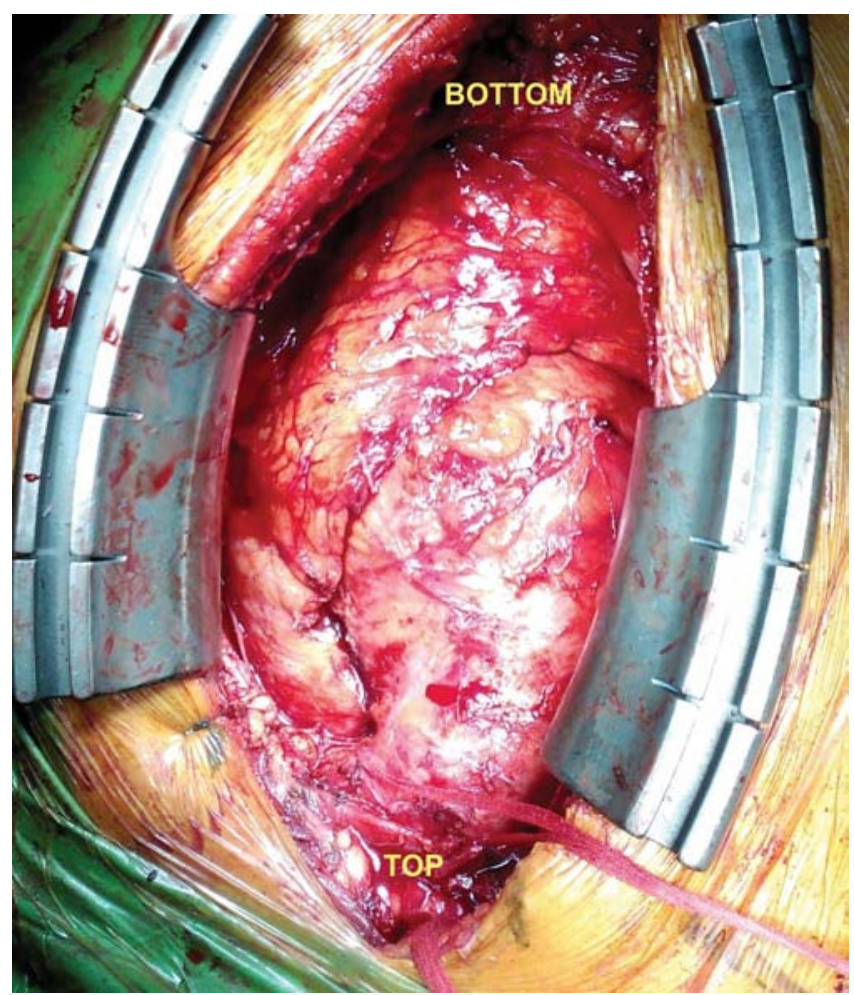

Figure 3. Intraoperative view of the aortic aneurysm.

\section{Discussion}

Aortic root replacement should be considered at the time of aortic valve replacement in young patients

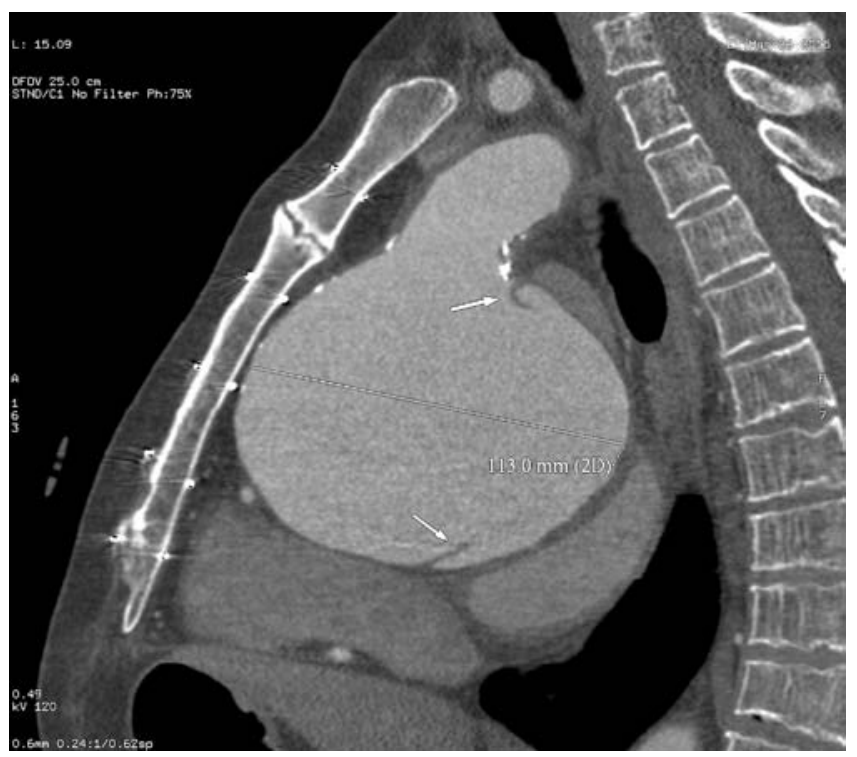

Figure 2. Computed tomography scan showing the giant aortic root aneurysm with an intimal flap (white arrows).

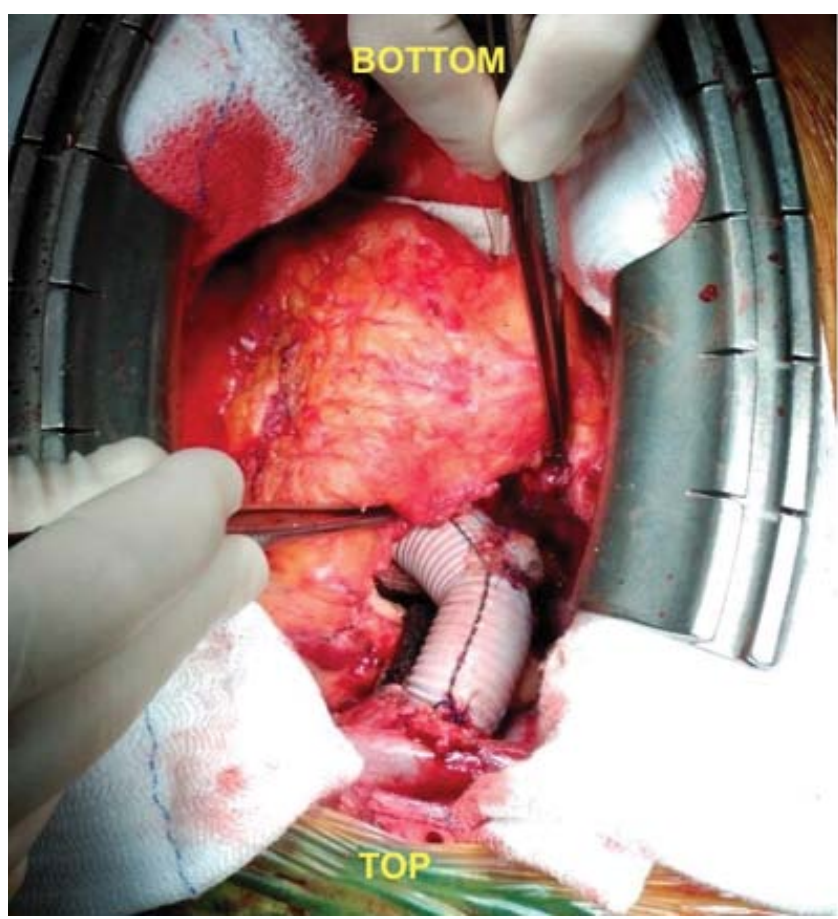

Figure 4. Bentall operation with Svensson modification.

with moderate enlargement of the ascending aorta and aortic annuloectasia, regardless of aortic valve phenotype. 


\section{Conflict of Interest}

The authors have no conflict of interest relevant to

\section{Comment on this Article or Ask a Question} this publication.

\section{Reference}

1. Svensson LG. Approach to the insertion of composite valve graft. Ann Thorac Surg. 1992;54:376-378. DOI: 10.1016/0003-4975(92)91409-3

Cite this article as: Puga AE, Rodríguez SC, Pañero BM, Moreira BC, López Almodóvar LF. Chronic Type A Aortic Dissection and Giant Aortic Root Aneurysm After Aortic Valve Replacement. AORTA (Stamford) 2016;4(3):108-110. DOI: http://dx.doi.org/10.12945/j. aorta.2016.15.028 